\title{
Article \\ Metal-Assisted Chemical Etching for Anisotropic Deep Trenching of GaN Array
}

\author{
Qi Wang ${ }^{1}{ }^{\oplus}$, Kehong Zhou ${ }^{1}$, Shuai Zhao ${ }^{2,3}{ }^{\oplus}$, Wen Yang ${ }^{1}$, Hongsheng Zhang ${ }^{1}$, Wensheng Yan ${ }^{1}$, Yi Huang ${ }^{1, *}$ \\ and Guodong Yuan ${ }^{2,3, *}$
}

check for updates

Citation: Wang, Q.; Zhou, K.; Zhao, S.; Yang, W.; Zhang, H.; Yan, W.; Huang, Y.; Yuan, G. Metal-Assisted Chemical Etching for Anisotropic Deep Trenching of GaN Array. Nanomaterials 2021, 11, 3179. https:// doi.org/10.3390/nano11123179

Academic Editor: Werner Blau

Received: 30 October 2021

Accepted: 21 November 2021

Published: 24 November 2021

Publisher's Note: MDPI stays neutral with regard to jurisdictional claims in published maps and institutional affiliations.

Copyright: (c) 2021 by the authors. Licensee MDPI, Basel, Switzerland. This article is an open access article distributed under the terms and conditions of the Creative Commons Attribution (CC BY) license (https:// creativecommons.org/licenses/by/ $4.0 /)$.
1 School of Optoelectronic Engineering, Chongqing University of Posts and Telecommunications, Chongqing 400065, China; wangqi@cqupt.edu.cn (Q.W.); S190431014@stu.cqupy.edu.cn (K.Z.); S200402033@stu.cqupt.edu.cn (W.Y.); zhanghs@cqupt.edu.cn (H.Z.); yws118@163.com (W.Y.)

2 State Key Laboratory for Superlattices and Microstructures, Institute of Semiconductors, Chinese Academy of Sciences, Beijing 100083, China; szhao@semi.ac.cn

3 College of Materials Science and Opto-Electronic Technology, University of Chinese Academy of Sciences, Beijing 100049, China

* Correspondence: huangy@cqupt.edu.cn (Y.H.); gdyuan@semi.ac.cn (G.Y.)

\begin{abstract}
Realizing the anisotropic deep trenching of GaN without surface damage is essential for the fabrication of GaN-based devices. However, traditional dry etching technologies introduce irreversible damage to $\mathrm{GaN}$ and degrade the performance of the device. In this paper, we demonstrate a damage-free, rapid metal-assisted chemical etching (MacEtch) method and perform an anisotropic, deep trenching of a GaN array. Regular GaN microarrays are fabricated based on the proposed method, in which $\mathrm{CuSO}_{4}$ and $\mathrm{HF}$ are adopted as etchants while ultraviolet light and Ni/ Ag mask are applied to catalyze the etching process of GaN, reaching an etching rate of $100 \mathrm{~nm} / \mathrm{min}$. We comprehensively explore the etching mechanism by adopting three different patterns, comparing a Ni/Ag mask with a SiN mask, and adjusting the etchant proportion. Under the catalytic role of $\mathrm{Ni} / \mathrm{Ag}$, the GaN etching rate nearby the metal mask is much faster than that of other parts, which contributes to the formation of deep trenches. Furthermore, an optimized etchant is studied to restrain the disorder accumulation of excessive $\mathrm{Cu}$ particles and guarantee a continuous etching result. Notably, our work presents a novel low-cost MacEtch method to achieve GaN deep etching at room temperature, which may promote the evolution of GaN-based device fabrication.
\end{abstract}

Keywords: wet etching; MacEtch; GaN; deep trenches; microstructures

\section{Introduction}

Metal-assisted chemical etching (MacEtch) is crucial for preparing complex micro/nano-structures such as pores, rings and pillars on Si and other compound semiconductors $[1,2]$. At present, $\mathrm{Si} / \mathrm{Ge}$ etching is the focus, and the progress of $\mathrm{Si}$ is much more mature [3]. The etching of III-V compounds ( $\mathrm{GaAs} / \mathrm{InP} / \mathrm{GaN}$ ) has also been carried out [4-6], but the etching mechanism of wide-bandgap semiconductors is imperfect and needs to be explored further. Unlike the traditional Si/Ge etching, the III-V semiconductor compounds have different characteristics. Additionally, the corresponding etching morphology and mechanism are not the same for different compounds. Etching conditions (assisted by temperature, electricity, and ultraviolet light) and the selection of oxidants/reductants all need to be explored [7-9]. The MacEtch technique has shown advantages in the etching of III-V semiconductor compounds with narrow bandgaps (such as GaAs) [10,11]. However, the research on wide-bandgap semiconductors (e.g., GaN) has not been completely established, especially for their deep etching [12,13]. Significant advantages in photoelectric devices have been shown in GaN due to its higher mobility and higher breakdown voltage [14-16]. Currently, GaN micro-/nano-structures are mainly prepared through bottom-up growth and top-down dry etching $[17,18]$. The epitaxial growth system is complex, and dry etching 
damages the material. Thus, a promising method, MacEtch, was studied to etch GaN micro-/nano-structures in $[19,20]$. This relatively simple approach does not damage GaN, which contributes to the better performance of devices. However, it is difficult to etch wide-bandgap $\mathrm{GaN}$ using conventional MacEtch because electron-hole pairs cannot be directly decomposed. An external force, such as a light or power source, is required to drive the anode decomposition of the semiconductor [21,22]. Though there are reports about $\mathrm{GaN}$ nanowires, few researchers have paid attention to the deep etching of GaN. In our previous work, $\mathrm{GaN}$ nanowires were obtained by applying ultraviolet light as the driving light source. Moreover, we found that the etching reaction stopped once the metal accumulated on the surface of the reaction sheet [23].

In this paper, we successfully realized uniform $\mathrm{GaN}$ microarrays with different depths via MacEtch using Ni/Ag as the mask. The process and reaction principle of MacEtch are presented in Section 2, while the scanning electron microscopy (SEM), atomic force microscopy (AFM) experimental results, and mechanism of MacEtch are shown in Section 3. We prove that the anisotropic, deep trenching of GaN microarrays can be rapidly prepared by the proposed MacEtch method.

\section{Materials and Methods}

The $6 \mu \mathrm{m}$-thick n-type GaN (nGaN) layer with a carrier concentration of $3.0 \times 10^{18} \mathrm{~cm}^{-3}$ is grown on a $2^{\prime \prime}$ sapphire substrate by metal organic chemical vapor deposition (MOCVD). First, $200 \mathrm{~nm}$ undoped $\mathrm{GaN}(\mathrm{uGaN}$ ) buffer layers are grown on the sapphire substrate, followed by the $6 \mu \mathrm{m}$-thick n-type GaN layer. Figure 1a-f shows the basic process flow of MacEtch for the preparation of the samples. Figure 1a shows the GaN sample, in which the scale of the sapphire substrate is adjusted for reading convenience. As shown in Figure 1b, the photoresist layer is spin coated on the GaN. Then, the photoresist is exposed and developed to generate patterns. Three different shapes are patterned on the GaN surface: micropillars with a $5 \mu \mathrm{m}$ diameter and $5 \mu \mathrm{m}$ gap; squares with a $50 \mu \mathrm{m}$ side and $5 \mu \mathrm{m}$ gap; and stripes with a $10 \mu \mathrm{m}$ width and $3 \mu \mathrm{m}$ gap, as shown in Figure 1c. A Ni/Ag $(100 / 300 \mathrm{~nm})$ layer is then deposited on the GaN surface by electron beam evaporation. The metal Ni/ Ag is usually applied as the mask in the MacEtch method due to its corrosion resistance. The sample after Ni/Ag lift-off is shown in Figure 1e. Additionally, the GaN chip is divided into squares with a $1 \mathrm{~cm}$ side after the $\mathrm{Ni} / \mathrm{Ag}$ is stripped and cleaned. These chips are put in the MacEtch etchant, as shown in Figure 1f. The etchant consists of a $0.01 \mathrm{M} \mathrm{CuSO}_{4}$ solution with $5 \mathrm{M} \mathrm{HF}$ and DI water. The etching time is 20 to $60 \mathrm{~min}$ under $300 \mathrm{~mW}$ ultraviolet (UV) light. Then, the chips are covered by a $\mathrm{Cu}$ film after the reaction, as shown in Figure 1g. The etched chips are placed in the diluted $\mathrm{HNO}_{3}$ solution for $10 \mathrm{~min}$ to remove the $\mathrm{Cu}$ particles and Ni/Ag mask. Finally, the etched chip shown in Figure $1 \mathrm{~h}$ is obtained.

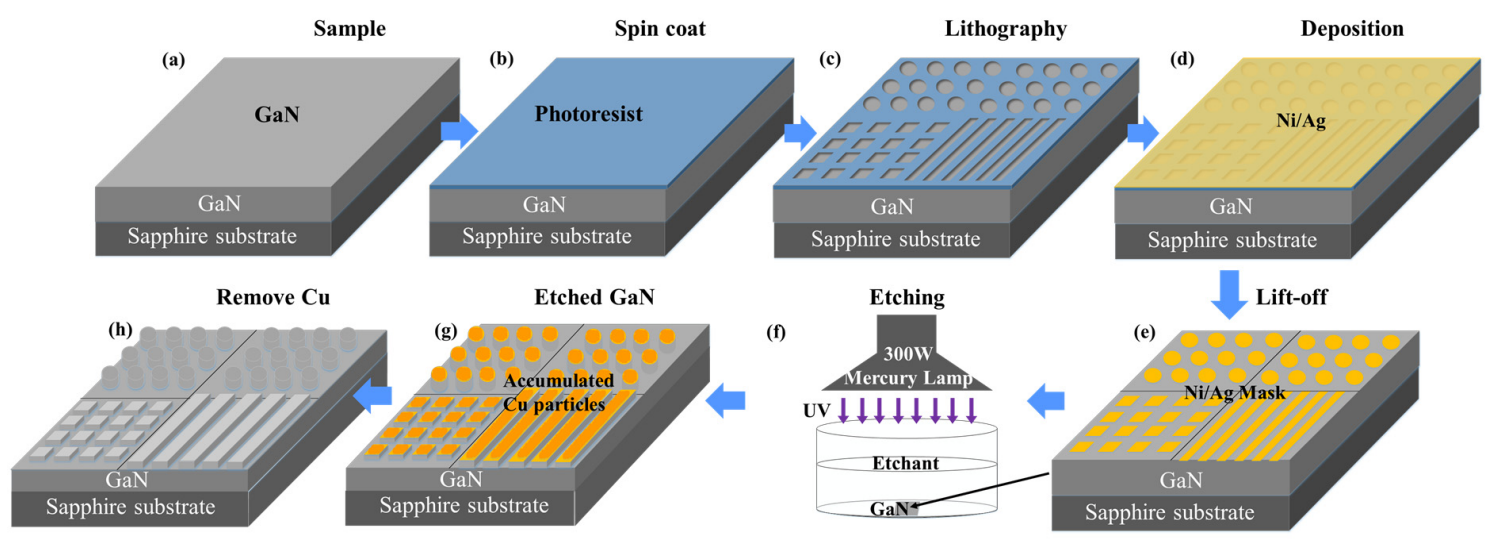

Figure 1. Schematic diagram showing the main steps of process flow in the fabrication of GaN: (a) GaN sample, (b) GaN coated by photoresist, (c) laser interference lithography, (d) Ni/Ag deposition, (e) Ni/Ag lift-off, (f) metal-assisted photochemical etching, (g) MacEtch of $\mathrm{GaN}$ and accumulation of $\mathrm{Cu}$ on $\mathrm{Ni} / \mathrm{Ag}$, and (h) etched GaN surface after $\mathrm{Cu}$ and $\mathrm{Ni} /$ Ag removal. 
The schematic diagram of the GaN MacEtch reaction is presented in Figure 2. The wide bandgap prevents GaN from being directly etched, and thus external forces such as electricity or UV light are needed to separate electron-hole pairs [24]. In this paper, UV illumination is applied to separate electron-hole pairs of GaN. The generation, transfer, and consumption of electron-hole pairs promote the continuous decomposition of GaN. As Figure 2 shows, the electrons and holes are separated under UV illumination. The valence electrons are excited from the valence band (VB) to the conduction band (CB) of GaN. Then, the excited electrons combine with $\mathrm{Cu}^{2+}$ to generate $\mathrm{Cu}$. Under the attraction of the metal mask, the generated $\mathrm{Cu}$ gradually forms on its edge. At the same time, the generated holes are consumed to preferentially oxidize $\mathrm{GaN}$ due to the higher oxidation potentials $\phi_{\mathrm{ox}}$ of $\mathrm{GaN}$ than the $\mathrm{O}_{2} / \mathrm{H}_{2} \mathrm{O}$ oxidation potential $\phi_{\mathrm{O}_{2} / \mathrm{H}_{2} \mathrm{O}}[25,26]$. Then, $\mathrm{Ga}^{3+}$ and $\mathrm{HF}$ react with each other, generating a kind of gallium fluoride [12,27]. The main reactions can be expressed as follows:

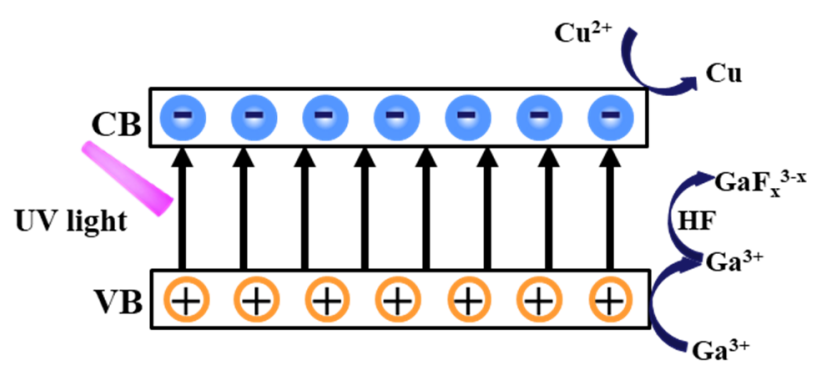

Figure 2. Schematic diagram of the MacEtch mechanism of GaN films.

Cathode:

$$
\mathrm{Cu}^{2+}+2 \mathrm{e}^{-} \rightarrow \mathrm{Cu}
$$

Anode:

$$
\begin{gathered}
2 \mathrm{GaN}+6 \mathrm{~h}^{+} \rightarrow 2 \mathrm{Ga}^{3+}+\mathrm{N}_{2} \uparrow \\
\mathrm{Ga}^{3+}+\mathrm{xHF} \rightarrow \mathrm{GaF}_{\mathrm{x}}^{3-\mathrm{x}}+\mathrm{xH}^{+}
\end{gathered}
$$

\section{Results and Discussion}

Three different GaN trench arrays are fabricated to reveal the characteristics of our proposed MacEtch method. The SEM images of micropillar, square, and stripe arrays are shown in Figure 3, demonstrating a good deep-etching capacity. Figure 3a shows the uniform array, which consists of micropillars with a $5 \mu \mathrm{m}$ diameter and $5 \mu \mathrm{m}$ spacing. Nevertheless, there is a certain inclination angle between the height and the plane of the micropillar, requiring some adjustment to improve the verticality of the sidewall. Compared with the micropillars array, the squares and stripes arrays present a better performance and verticality of the sidewall, as shown in Figure 3b,c. The grooves present noticeable edges and angles, as well as a relatively high verticality of the sidewall.

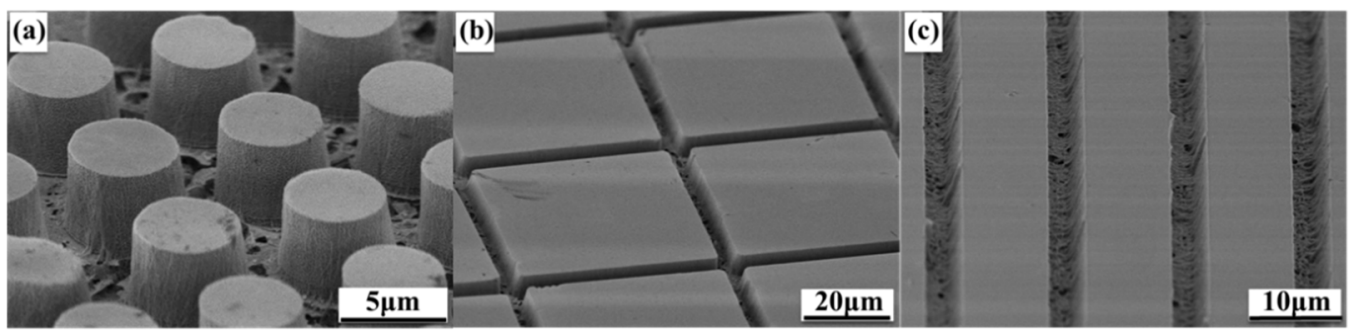

Figure 3. Cross-sectional SEM images ( $45^{\circ}$-tilt view) of the etched GaN microstructures with different shapes: (a) micropillars, (b) squares, and (c) stripes. 
The stripe grooves etched for different durations $(20,40$, and $60 \mathrm{~min})$ can be observed in Figure 4. Due to the high hardness of sapphire substrates, it is difficult to ensure a straight cleaved section. Thus, the groove orientations are different in SEM images to observe the regions where the cross sections are approximately vertical. The red tag in Figure 4a marks a V-type angle between the horizontal and vertical directions at the bottom of the groove. Because the catalysis of the accumulated $\mathrm{Cu}$ on the stripe edge speeds up the reaction, the area nearby the $\mathrm{Ni} / \mathrm{Ag}$ mask is etched first; then, the V-type angle forms. The etching rate in the vertical direction is larger than that in the horizontal one, which causes the horizontal width to narrow after a period of etching. Then, the inverted trapezoidal groove, together with an obvious V-type angle, occurs after a 20 min etching, as shown in Figure $4 \mathrm{a}$.

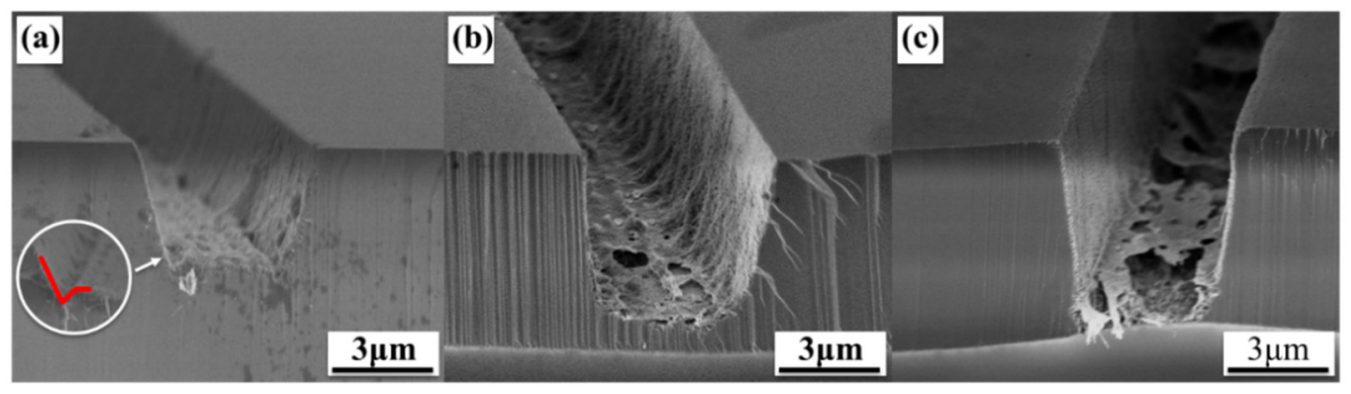

Figure 4. Cross-sectional SEM images ( $45^{\circ}$-tilt view) of the etched GaN stripe structures with different etching times: (a) $20 \mathrm{~min}$, (b) $40 \mathrm{~min}$, and (c) $60 \mathrm{~min}$.

However, the angle starts to become smaller as the reaction progresses, as shown in Figure $4 \mathrm{~b}$. There is a thin film layer at the groove bottom in Figure $4 \mathrm{c}$, which comes from the inserted $\mathrm{uGaN}$ buffer layer during the GaN epitaxial growth. In detail, the film is the product of the transition from the $\mathrm{uGaN}$ to an $\mathrm{nGaN}$ layer. When the etching goes through the $\mathrm{nGaN}$ to the $\mathrm{uGaN}$ layer, the etching slows due to the decreased doping concentration. The strong binding force produced by the fusion of $\mathrm{uGaN}$ and $\mathrm{nGaN}$ at the interface causes difficulty in etching the interface layer. The vertical etching starts to slow down while the speed of horizontal etching stays the same because of the film's barrier. On this occasion, the V-type angle becomes flat and the sidewall verticality becomes higher after 40 min of etching. Finally, the uGaN buffer layer is fully etched, while the interface between uGaN and $\mathrm{nGaN}$ is partly etched after $60 \mathrm{~min}$. In Figure 4c, the remaining partly etched interface layer between $\mathrm{uGaN}$ and $\mathrm{nGaN}$ is suspended. Furthermore, the MacEtch method can also be applied to etch $\mathrm{uGaN}$. In this paper, excellent $\mathrm{GaN}$ etching is achieved based on the proposed method.

Notably, the cylindrical structure in Figure 3a is with a large horizontal etching range, resulting in a limited reduction in the V-type angle, which causes the micropillars to present a slightly lower sidewall verticality than other patterns. In addition, the etched sidewall appears to have a porous structure, which is a sign of lateral etching. When the reaction starts, nanopores form on the sample surface, and ultraviolet light penetrates along them, making the reaction extend deeply. However, the interaction between the sidewall and ultraviolet light is weak, giving rise to a slow reaction. This is another main reason why the etching rate in the vertical direction is larger than that in the horizontal direction. It can also be seen from Figure 4 that the vertical height reaches about 3, 4.5, and $6 \mu \mathrm{m}$ after etching for 20,40, and $60 \mathrm{~min}$, respectively, meaning that the etching rate reaches up to $\sim 100 \mathrm{~nm} / \mathrm{min}$; meanwhile, the obtained trench arrays are uniform. Note that this high etching rate is realized with MacEtch at room temperature, and it is believed to be further improved by raising the reaction temperature. Furthermore, this result is comparable with the photoelectrochemical (PEC) etching rate $(\sim 0.2-100 \mathrm{~nm} / \mathrm{min})$ reported in previous work $[28,29]$. 
The AFM images of the etched sample with 60 and 90 min etching are used in the qualitative analyses of sample surface roughness, as shown in Figure $5 a, b$. The corresponding arithmetic mean roughness $R_{a}$ values in the $1 \mu \mathrm{m}^{2}$ square area measurement are $7.565 \mathrm{~nm}$ when the etching time is $60 \mathrm{~min}$, and this value is $0.480 \mathrm{~nm}$ when the etching time is $90 \mathrm{~min}$. At the beginning of etching, holes are formed on the GaN surface, causing the roughness to increase. However, as the reaction progresses, the etched surface gradually flattens and the roughness decreases.

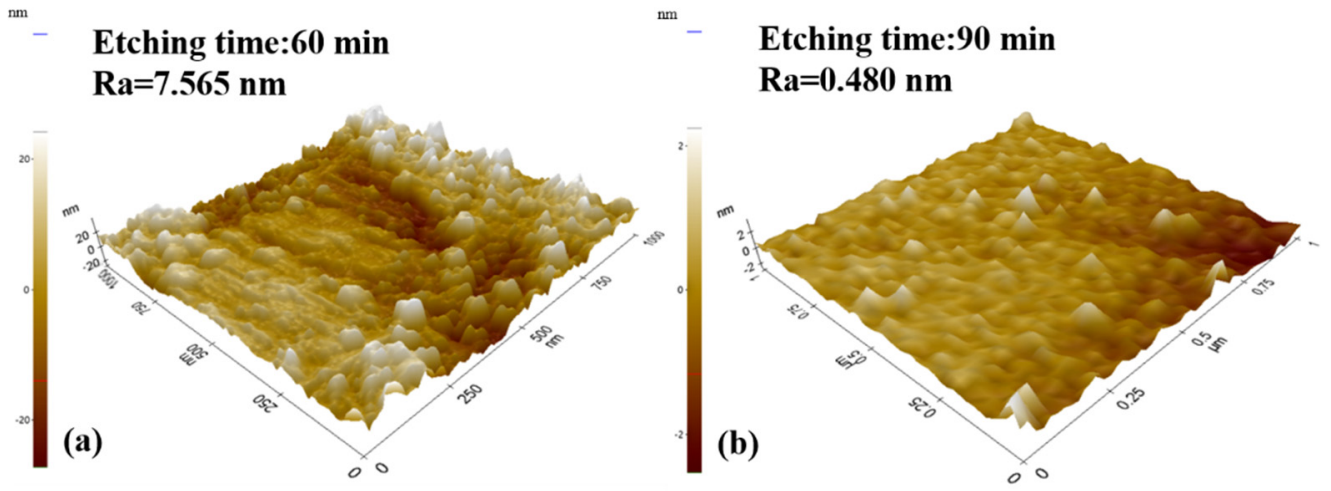

Figure 5. AFM images of the etched surface: (a) etching $60 \mathrm{~min}$ and (b) etching $90 \mathrm{~min}$.

The principle of the proposed MacEtch method is illustrated in Figure 6, which is an electrochemical reaction when the $\mathrm{GaN}$ is etched. It is well established that as-generated electron-hole pairs in $\mathrm{GaN}$ separate and diffuse in the semiconductor under ultraviolet light irradiation. Then, the holes directly oxidize $\mathrm{GaN}$ to generate $\mathrm{Ga}_{2} \mathrm{O}_{3}$ and the $\mathrm{Ga}_{2} \mathrm{O}_{3}$ is dissolved under the action of $\mathrm{HF}$, realizing the $\mathrm{GaN}$ etching. At the same time, the $\mathrm{Cu}$ ions obtain electrons to produce $\mathrm{Cu}$ particles which accumulate on the metal-mask surfaces because of the attraction. The $\mathrm{Cu}$ particles begin to deposit around the mask edge, which catalyze the reaction nearby the mask, giving rise to the difference between vertical and lateral etching rates. This is the reason why V-type angles form at the beginning. Though anisotropic etching of $\mathrm{GaN}$ is realized in this paper, more optimizations are needed to further improve the verticality of the sidewall based on this theory.

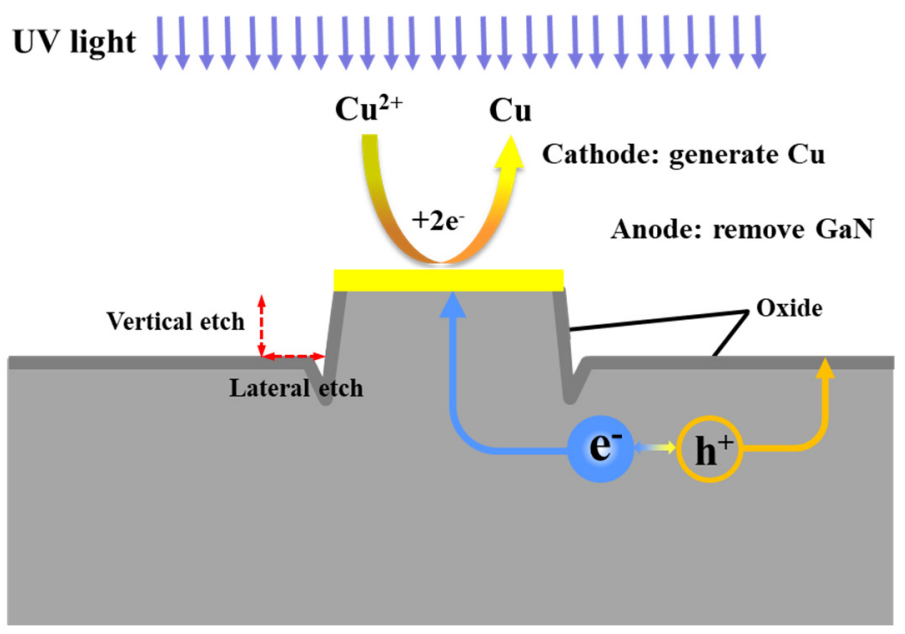

Figure 6. Illustration of the metal-assisted chemical etching mechanism of GaN.

\subsection{Selection of Mask Materials}

The catalysis of metal is a key element in the MacEtch process. To explore the function of the $\mathrm{Ni}$ / Ag mask, we introduce another nonmetallic material ( $\mathrm{SiN}$ ) as the etching mask for comparison. Figure $7 \mathrm{a}, \mathrm{b}$ shows the $\mathrm{GaN}$ microstructures etched for $40 \mathrm{~min}$ with a 
$100 \mathrm{~nm} / 300 \mathrm{~nm} \mathrm{Ni} / \mathrm{Ag}$ mask, and Figure 7c,d presents the GaN microstructures etched for 60 min with a $400 \mathrm{~nm} \mathrm{SiN} \mathrm{mask.} \mathrm{It} \mathrm{can} \mathrm{be} \mathrm{observed} \mathrm{in} \mathrm{Figure} \mathrm{7a,b} \mathrm{that} \mathrm{a} \mathrm{large} \mathrm{amount}$ of reaction-generated particles appear and pile up on the $\mathrm{Ni} / \mathrm{Ag}$ mask surface (especially at the mask edge), while particles in other areas are scarce. These particles are proved to be $\mathrm{Cu}$, and this phenomenon may be related to the metal mask's attraction to copper ions. The $\mathrm{Cu}$ particles preferentially nucleate at these sites. As for the etched sample using a SiN mask (see Figure 7c,d), there are no massive $\mathrm{Cu}$ particles on the SiN mask surface. Furthermore, many smaller GaN micropillars occur in the maskless area. It can be inferred that the nonmetallic SiN mask possesses a poor ability to attract $\mathrm{Cu}^{2+}$, and thus the reaction-generated $\mathrm{Cu}$ particles preferentially nucleate and grow at other regions (defective sites). These $\mathrm{Cu}$ particles, serving as small irregularly shaped metal masks, effectively block the UV illumination at certain regions during the MacEtch process, inducing the formation of small GaN micropillars. However, such $\mathrm{Cu}$ particles may be spontaneously lifted off after the whole process due to the weak metal-semiconductor bonding force, and there are few $\mathrm{Cu}$ particles that can be observed after etching. Under this circumstance, we find that the randomly distributed $\mathrm{GaN}$ micropillars can be effectively avoided by adopting the $\mathrm{Ni} / \mathrm{Ag}$ mask during MacEtch, and this metal mask is more conducive to the fabrication of regular $\mathrm{GaN}$ trench arrays.

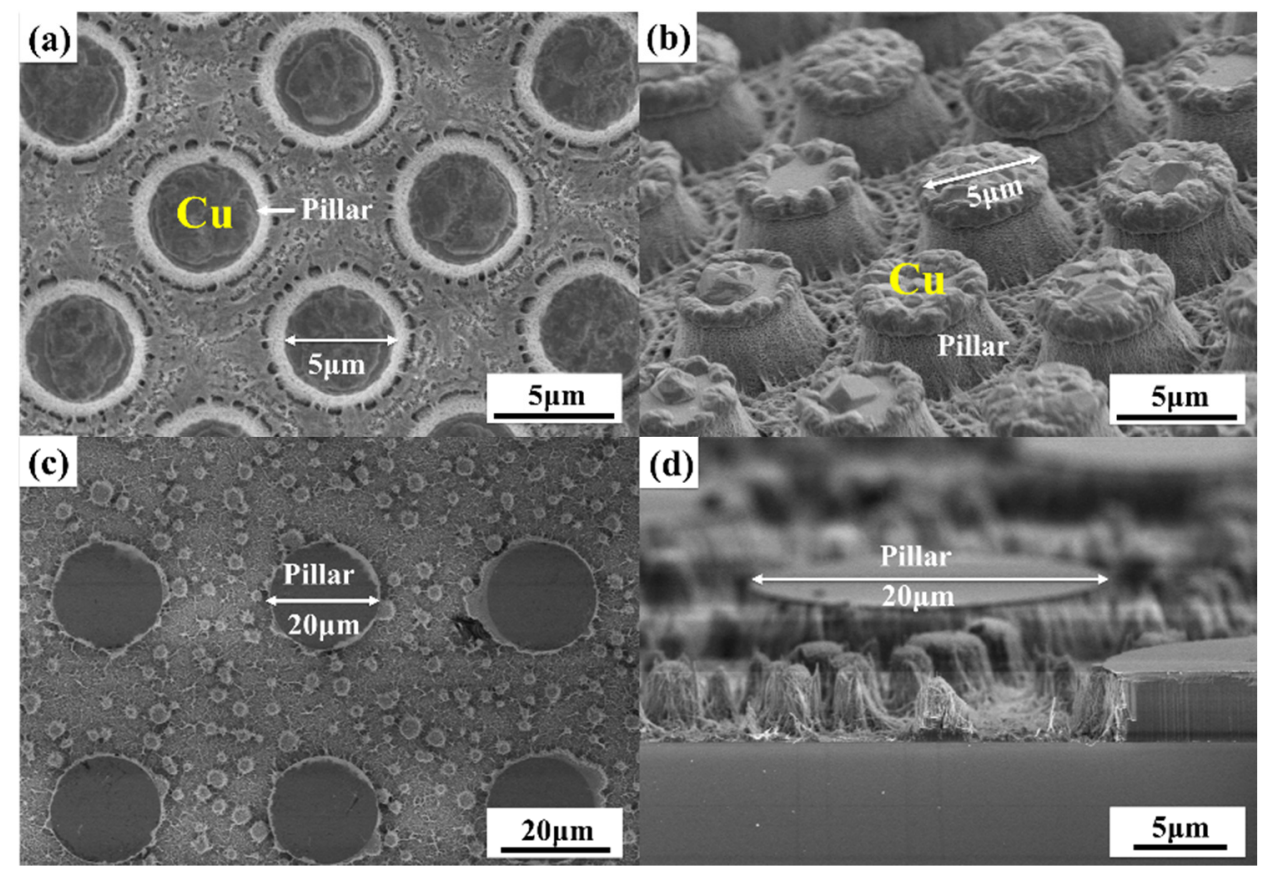

Figure 7. Plane view and cross-sectional SEM images of the obtained GaN microstructures using MacEtch with different mask materials: (a,b) Ni/Ag mask and (c,d) SiN mask.

\subsection{Effect of HF Concentration on GaN MacEtch}

The HF concentration plays another key role in GaN MacEtch. The as-prepared GaN micropillar arrays with two different HF concentrations are studied in this section. The etching time is $30 \mathrm{~min}$ and the etching mask is $\mathrm{Ni} / \mathrm{Ag}$. Figure $8 \mathrm{a}$,c shows the SEM images ( $45^{\circ}$-tilt view) of the etched $\mathrm{GaN}$ micropillar arrays with $5 \mathrm{M}$ and $10 \mathrm{M} \mathrm{HF}$ concentrations, respectively. Figure $8 b$,d presents the magnified SEM images of Figure 8a,c. Counterintuitively, the GaN pillar height obtained from the etchant containing $5 \mathrm{M} \mathrm{HF}$ is higher than that obtained with $10 \mathrm{M} \mathrm{HF}$. The $\mathrm{Cu}$ particle distributions can also be observed in Figure 8. As mentioned, $\mathrm{Cu}$ particles accumulate only on the mask surface after the sample is etched in a $5 \mathrm{M}$ HF-containing etchant. As for the $10 \mathrm{M}$ HF-processed sample, $\mathrm{Cu}$ particles heap up at the mask surface and at the micropillar sidewall. 


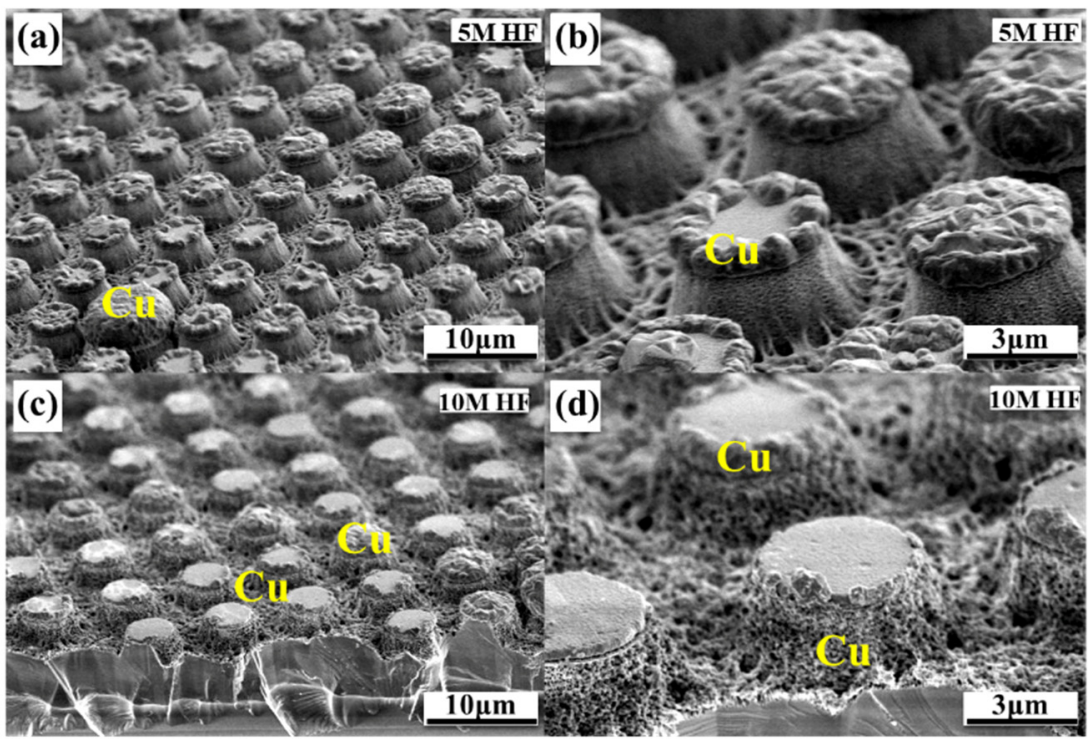

Figure 8. Cross-sectional SEM images ( $45^{\circ}$-tilt view) of the $\mathrm{GaN}$ micropillar arrays obtained with etchants containing different HF concentrations: (a,b) $5 \mathrm{M}$ and (c,d) $10 \mathrm{M}$.

A schematic diagram is depicted and shown in Figure 9 to further reveal the role of the HF concentration on $\mathrm{GaN}$ etching. The orange dots represent $\mathrm{Cu}$ particles while the yellow bars represent the $\mathrm{Ni} / \mathrm{Ag}$ masks. It can be observed from Figure 9a (corresponding to Figure $8 \mathrm{~b}$ ) that the generated $\mathrm{Cu}$ particles mainly accumulate on the edge and the surface of the mask. Additionally, the generated Cu particles spread over the whole sample surface including the pillar sidewalls after etching, as shown in Figure $9 \mathrm{~b}$ (corresponding to Figure 8d). The increasing HF concentration accelerates the decomposition of $\mathrm{GaN}$ and the consumption of the holes (anode reaction). Accordingly, the cathodic $\mathrm{Cu}$ generation reaction rate is also elevated, and thus many more $\mathrm{Cu}$ particles come into being and spread over the whole wafer. These excessive $\mathrm{Cu}$ particles wrap the whole pillar sidewalls and cover the bottom maskless regions, blocking the UV light penetration and thus reducing the etching rate. In this situation, the obtained micropillars have a short structure. Therefore, it is vital to adopt a specific etchant in order to ensure the etching rate and etched morphology, and in our work the optimized $\mathrm{CuSO}_{4} / \mathrm{HF}$ molar ratio is 0.02:5.
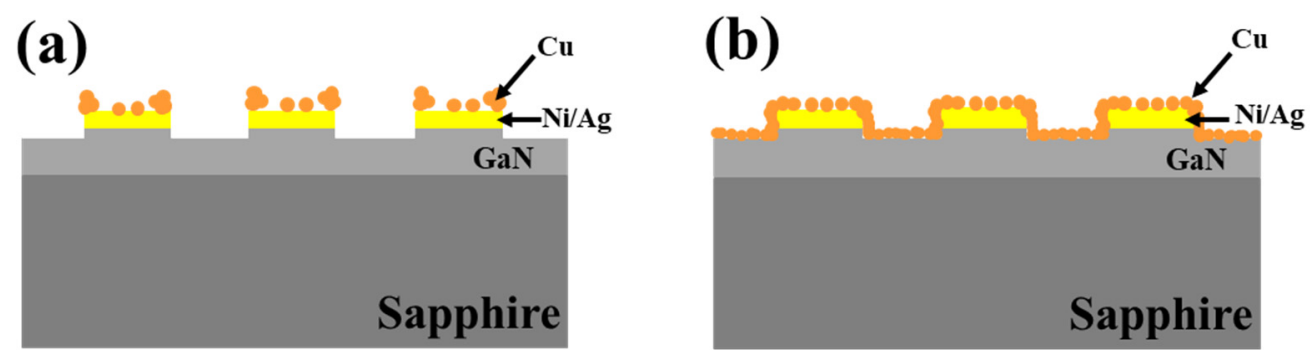

Figure 9. Schematic illustrations for $\mathrm{Cu}$ distributions in the GaN MacEtch process with different etchants where the HF concentration is: (a) low; (b) high.

\section{Conclusions}

We demonstrate a novel MacEtch method and realize the rapid and anisotropic deep etching of GaN. Regular GaN microarrays, including micropillar, square, and stripe arrays, are fabricated by this method, and the etching rate can reach $100 \mathrm{~nm} / \mathrm{min}$. Moreover, the characteristics and mechanism of the MacEtch are explored through analyzing the effects of the mask material, UV illumination, and etchant proportion. The catalytic action of the $\mathrm{Ni} / \mathrm{Ag}$ mask affects the etching rate and benefits the formation of deep trenches. The UV light drives the separation of electron-hole pairs in $\mathrm{GaN}$, and the specific etchant with an 
optimized $\mathrm{CuSO}_{4} / \mathrm{HF}$ ratio may ensure the orderly accumulation of $\mathrm{Cu}$ particles, resulting in a continuous $\mathrm{GaN}$ trenching. Additionally, the blocking effect of the $\mathrm{uGaN} / \mathrm{nGaN}$ combination layer contributes to a high sidewall verticality. This work offers a low-cost, rapid, anisotropic deep-etching technique for the preparation of GaN microarrays at room temperature, bringing a new promise for potential $\mathrm{GaN}$ device fabrication. Meanwhile, we provide a new physical insight into GaN deep etching, paving a new way for future wide-bandgap semiconductor etching.

Author Contributions: Validation, Y.H., G.Y. and H.Z.; formal analysis, Q.W.; resources, Y.H., G.Y. and. W.Y. (Wensheng Yan); data curation, K.Z., W.Y. (Wen Yang) and S.Z.; investigation Q.W., S.Z., W.Y. (Wen Yang) and K.Z.; writing—original draft preparation, Q.W.; writing—review and editing, Q.W.; supervision, Y.H., G.Y. and W.Y. (Wensheng Yan). All authors have read and agreed to the published version of the manuscript.

Funding: This research was funded by the Technology Innovation and Application Demonstration Key Project of Chongqing Municipality (cstc2019jszx-zdztzxX0005), the Technology Innovation and Application Demonstration Key Project of Chongqing Municipality (cstc2020jscx-gksbX0011), the Chongqing Basic and Frontier Research Project (cstc2018jcyjAX0209), and the Science and Technology Research Program of Chongqing Municipal Education Commission (KJQN202100614).

Institutional Review Board Statement: Not applicable.

Informed Consent Statement: Not applicable.

Data Availability Statement: All data used to support the findings of this study are included within the article.

Conflicts of Interest: The authors declare no conflict of interest.

\section{References}

1. Zhao, S.; Yuan, G.; Wang, Q.; Liu, W.; Zhang, S.; Liu, Z.; Wang, J.; Li, J. Morphology control of c-Si via facile copper-assisted chemical etching: Managements on etch end-points. Appl. Surf. Sci. 2019, 489, 776. [CrossRef]

2. Toor, F.; Miller, J.B.; Davidson, L.M.; Duan, W.; Jura, M.P.; Yim, J.; Forziati, J.; Black, M.R. Metal assisted catalyzed etched (MACE) black Si: Optics and device physics. Nanoscale 2016, 8, 15448. [CrossRef] [PubMed]

3. Huang, Z.; Geyer, N.; Werner, P.; de Boor, J.; Gosele, U. Metal-assisted chemical etching of silicon: A review. Adv. Mater. 2011, 23, 285. [CrossRef] [PubMed]

4. Wilhelm, T.S.; Wang, Z.; Baboli, M.A.; Yan, J.; Preble, S.F.; Mohseni, P.K. Ordered AlxGa1-xAs Nanopillar Arrays via Inverse Metal-Assisted Chemical Etching. ACS Appl. Mater. Interfaces 2018, 10, 27488. [CrossRef] [PubMed]

5. Kim, S.H.; Mohseni, P.K.; Song, Y.; Ishihara, T.; Li, X. Inverse metal-assisted chemical etching produces smooth high aspect ratio InP nanostructures. Nano Lett. 2015, 15, 641. [CrossRef] [PubMed]

6. Geng, X.; Duan, B.K.; Grismer, D.A.; Zhao, L.; Bohn, P.W. Monodisperse GaN nanowires prepared by metal-assisted chemical etching with in situ catalyst deposition. Electrochem. Commun. 2012, 19, 39. [CrossRef]

7. Miwa, K.; Komatsu, Y.; Toguchi, M.; Horikiri, F.; Fukuhara, N.; Narita, Y.; Ichikawa, O.; Isono, R.; Tanaka, T.; Sato, T. Selftermination of contactless photo-electrochemical (PEC) etching on aluminum gallium nitride/gallium nitride heterostructures. Appl. Phys. Express 2020, 13, 026508. [CrossRef]

8. Zhang, M.R.; Hou, F.; Wang, Z.G.; Zhang, S.H.; Pan, G.B. Photoelectrochemical etching of gallium nitride surface by complexation dissolution mechanism. Appl. Surf. Sci. 2017, 410, 332. [CrossRef]

9. Horikiri, F.; Fukuhara, N.; Ohta, H.; Asai, N.; Narita, Y.; Yoshida, T.; Mishima, T.; Toguchi, M.; Miwa, K.; Ogami, H.; et al. Thermal-assisted contactless photoelectrochemical etching for GaN. Appl. Phys. Express 2020, 13, 046501. [CrossRef]

10. Asoh, H.; Suzuki, Y.; Ono, S. Metal-assisted chemical etching of GaAs using Au catalyst deposited on the backside of a substrate. Electrochim. Acta 2015, 183, 8. [CrossRef]

11. Kong, L.; Song, Y.; Kim, J.D.; Yu, L.; Wasserman, D.; Chim, W.K.; Chiam, S.Y.; Li, X. Damage-Free Smooth-Sidewall InGaAs Nanopillar Array by Metal-Assisted Chemical Etching. ACS Nano 2017, 11, 10193. [CrossRef] [PubMed]

12. Najar, A.; Shafa, M.; Anjum, D. Synthesis, optical properties and residual strain effect of GaN nanowires generated via metalassisted photochemical electroless etching. RSC Adv. 2017, 7, 21697. [CrossRef]

13. Horikiri, F.; Fukuhara, N.; Ohta, H.; Asai, N.; Narita, Y.; Yoshida, T.; Mishima, T.; Toguchi, M.; Miwa, K.; Sato, T. Simple wet-etching technology for GaN using an electrodeless photo-assisted electrochemical reaction with a luminous array film as the UV source. Appl. Phys. Express 2019, 12, 031003. [CrossRef]

14. Tong, X.W.; Kong, W.Y.; Wang, Y.Y.; Zhu, J.M.; Luo, L.B.; Wang, Z.H. High-Performance Red-Light Photodetector Based on Lead-Free Bismuth Halide Perovskite Film. ACS Appl. Mater. Interfaces 2017, 9, 18977. [CrossRef] [PubMed] 
15. Sun, Y.; Zhou, K.; Sun, Q.; Liu, J.; Feng, M.; Li, Z.; Zhou, Y.; Zhang, L.; Li, D.; Zhang, S.; et al. Room-temperature continuous-wave electrically injected InGaN-based laser directly grown on Si. Nat. Photonics 2016, 10, 595. [CrossRef]

16. Gao, J.; Jin, Y.; Hao, Y.; Xie, B.; Wen, C.P.; Shen, B.; Wang, M. Gate-Recessed Normally OFF GaN MOSHEMT With HighTemperature Oxidation/Wet Etching Using LPCVD Si ${ }_{3} \mathrm{~N}_{4}$ as the Mask. IEEE Trans. Electron Dev. 2018, 65, 1728. [CrossRef]

17. Sun, Y.; Kang, X.; Zheng, Y.; Wei, K.; Li, P.; Wang, W.; Liu, X.; Zhang, G. Optimization of Mesa Etch for a Quasi-Vertical GaN Schottky Barrier Diode (SBD) by Inductively Coupled Plasma (ICP) and Device Characteristics. Nanomaterials 2020, $10,657$. [CrossRef]

18. Kochetkov, F.M.; Neplokh, V.; Mastalieva, V.A.; Mukhangali, S.; Vorob'ev, A.A.; Uvarov, A.V.; Komissarenko, F.E.; Mitin, D.M.; Kapoor, A.; Eymery, J.; et al. Stretchable Transparent Light-Emitting Diodes Based on InGaN/GaN Quantum Well Microwires and Carbon Nanotube Films. Nanomaterials 2021, 11, 1503. [CrossRef]

19. Zhang, M.R.; Jiang, Q.M.; Zhang, S.H.; Wang, Z.G.; Hou, F.; Pan, G.B. Fabrication of gallium nitride nanowires by metal-assisted photochemical etching. Appl. Surf. Sci. 2017, 422, 216. [CrossRef]

20. Aravindh, S.A.; Xin, B.; Mitra, S.; Roqan, I.S.; Najar, A. GaN and InGaN nanowires prepared by metal-assisted electroless etching: Experimental and theoretical studies. Results Phys. 2020, 19, 103428. [CrossRef]

21. Huygens, I.M.; Strubbe, K.; Gomes, W.P. Electrochemistry and Photoetching of n-GaN. J. Electrochem. Soc. 2000, $147,1797$. [CrossRef]

22. Zhuang, D.; Edgar, J.H. Wet etching of GaN, AlN, and SiC: A review. Mater. Sci. Eng. R 2005, 48, 1. [CrossRef]

23. Wang, Q.; Yuan, G.; Zhao, S.; Liu, W.; Liu, Z.; Wang, J.; Li, J. Metal-assisted photochemical etching of GaN nanowires: The role of metal distribution. Electrochem. Commun. 2019, 103, 66. [CrossRef]

24. Pearton, S.J.; Zolper, J.C.; Shul, R.J.; Ren, F. GaN: Processing, defects, and devices. J. Appl. Phys. 1999, 86, 1. [CrossRef]

25. Chen, S.; Wang, L.W. Thermodynamic Oxidation and Reduction Potentials of Photocatalytic Semiconductors in Aqueous Solution. Chem. Mater. 2012, 24, 3659. [CrossRef]

26. Geng, X.; Duan, B.K.; Grismer, D.A.; Zhao, L.; Bohn, P.W. Catalyst and processing effects on metal-assisted chemical etching for the production of highly porous GaN. Semicond. Sci. Technol. 2013, 28, 065001. [CrossRef]

27. Sujatha, K.; Israel, S.; Anzline, C.; Devi, R.N.; Sheeba, R.A.J.R. X-ray derived experimental charge density distribution in GaF3 and VF3 solid systems. Phys. B Condens. Matter 2016, 496, 74. [CrossRef]

28. Horikiri, F.; Ohta, H.; Asai, N.; Narita, Y.; Yoshida, T.; Mishima, T. Excellent potential of photo-electrochemical etching for fabricating high-aspect-ratio deep trenches in gallium nitride. Appl. Phys. Express 2018, 11, 091001. [CrossRef]

29. Mokhov, D.V.; Berezovskaya, T.N.; Nikitina, E.V.; Shubina, K.Y.; Mizerov, A.M.; Bouravleuv, A.D. Metal-Assisted Photochemical Etching of N- and Ga-Polar GaN Epitaxial Layers. Semiconductors 2019, 53, 1717. [CrossRef] 